\title{
Assessment of the Microstructure and Mechanical Properties of a Laser-Joined Carbon Fiber-Reinforced Thermosetting Plastic and Stainless Steel
}

\author{
L. Y. Sheng, ${ }^{a, 1}$ J. K. Jiao, ${ }^{b, 2}$ and C. Lai ${ }^{a}$ \\ ${ }^{a}$ Shenzhen Institute, Peking University, Shenzhen, China \\ ${ }^{\mathrm{b}}$ Ningbo Institute of Materials Technology and Engineering, Chinese Academy of Sciences, Ningbo, \\ China \\ 1 lysheng@yeah.net \\ 2 jiaojunke@nimte.ac.cn
}

The thermosetting plastic and stainless steel were joined with a fiber laser. The influence of processing parameters on the joint was studied. The laser scanning on stainless steel is shown to result in the formation of the heat-affected and fusion zones. In the first zone, lathy ferrite precipitates along the boundary, which modifies austenite, while in the second zone, ferrite forms the skeleton structure and separates austenite into a small cellular structure. The laser joining improves the microstructure of both zones. With an increase in the laser scanning speed and power, the shear strength of the stainless steel/plastic joint first increases and then decreases. A low laser scanning speed or high laser power would overheat polyphenylene sulphide and lead to its decomposition. Those factors would also reduce heat transfer and lead to its insufficient melting. The stainless steel/plastic joint acquires a maximum shear strength at a laser scanning speed of 4-5 mm/s and laser power of 320-350 W.

Keywords: laser joining, carbon fiber-reinforced thermoplastic, stainless steel, microstructure, shear strength, bonding interface.

Introduction. Recently, the carbon fiber reinforced polymer (CFRP) has been received much attention, because of its advantages, such as high specific stiffness, low density, excellent corrosion resistance, high strength to weight ratios, good environmental degradation and fatigue resistance, etc. [1, 2]. Therefore, it has been applied as the structural material in lots of fields, such as aerospace, concrete structure, automotive, electronic and so on [3, 4]. However, the wide application of the CFRP inevitably encounters the problem of how to join the CFRP with the metal-based components. In general, the joining between metals and CFRP could be performed by the adhesive bonding, thermal and mechanical joining. Among them, the mechanical joining has been considered as a convenient way with high efficiency. However, due to the characteristics of the CFRP, the conventional mechanical joining could not join the CFRP on metal without the damage on CFRP [5]. The research [6] on the double-lap joints of aluminum and CFRP laminate by rivets arrays exhibited that the initial delamination near the CFRP hole edge could influence the strength of the joint because the crack or delamination could grow rapidly along the initial damage region. Kweon et al. [7] exhibited that the Al/CFRP double lap joint with adhesive bonding and bolt insertion could improve the mechanical properties. However, the hybrid joint also destroyed the microstructure of CFRP and influenced its strength and fatigue properties [8]. Though the adhesive bonding has no damage on the CFRP, its low bonding strength and long cure processing restrict its application. Therefore, it is necessary to develop processing technology without damage to the carbon fiber and polymer.

The polyphenylene sulfide (PPS) based carbon fiber reinforced thermoplastic (CFRTP) is a kind of carbon fiber reinforced polymer with good thermo-process feature and the main advantages of CFRP so that it can be joined with the metal by thermal 
processing. The recent studies [9, 10] exhibited the CFRTP and metal could be joined together by the friction stir method, which took use of the heat from the friction stirring metal to melt the CFRTP and fixed the metal and CFRTP. Though the friction stir could decrease the damage of the CFRTP, the stress would concentrate along the friction stirred hole and then lead to the failure of the CFRTP. Katayama and Kawahito [11] exhibited that the direct laser irradiated on stainless steel could generate a $\mathrm{Cr}_{2} \mathrm{O}_{3}$ transition layer on the interface of plastic/stainless steel. Moreover, the research of Tan et al. [12] revealed that the shear strength of the CFRP/steel joint was improved by the existence of $\mathrm{Cr}$ layer on the steel surface because it could form the Cr-O-PA6T bonding along the joint interface. The study of Tan et al. [13] revealed that the heat from the laser would result in rapid temperature increases, which could generate the $\mathrm{CO}_{2}, \mathrm{NH}_{3}$, and $\mathrm{H}_{2} \mathrm{O}$ in the CFRP and promote the air bubbles and porosity. Based on the previous researches [14, 15], the formation of defects along the joining interface influenced the mechanical properties. Then it became important how to decrease the formation of porosity during the laser joining CFRTP and metal.

Based on the previous researches, it could be found that they mainly focused on the interface and the bonding mechanism of the joint between CFRTP and steel. However, until now, few works have been done to study the effect of laser joining processing parameters on microstructure and mechanical properties of CFRTP and steel. Therefore, in the present paper, the joint of the CFRTP and stainless steel was prepared by the fiber laser with various laser power and laser scanning speed. The microstructure, joint interface and mechanical properties of the joints were investigated to obtain the optimal processing parameters.

\section{Experimental Procedures.}

1.1. Materials. In this study, the CFRTP panels with PPS matrix reinforced by T700 carbon fibers were cut in size of $50 \times 30 \times 3 \mathrm{~mm}$, and the stainless steel plate with a size of $50 \times 30 \times 2 \mathrm{~mm}$ were prepared. The stainless steel surface for bonding was scratch brushed by the $120 \#$ abrasive paper to increase the roughness. The CFRTP is composed by PPS matrix and 15 layers T700 carbon fibers, which is weaved with intersected structure. The carbon fiber is wrapped by the PPS, and the average thickness of a single layer is about $200 \mu \mathrm{m}$. Table 1 shows the chemical composition of the stainless steel.

$\mathrm{T}$ a b 1 e 1

The Chemical Composition of the Stainless Steel (wt.\%)

\begin{tabular}{|c|c|c|c|c|c|c|c|c|}
\hline $\mathrm{C}$ & $\mathrm{Mn}$ & $\mathrm{Mo}$ & $\mathrm{Ni}$ & $\mathrm{Cr}$ & $\mathrm{Si}$ & $\mathrm{S}$ & $\mathrm{P}$ & $\mathrm{Fe}$ \\
\hline 0.06 & 0.98 & 2.16 & 12.36 & 17.56 & 0.48 & 0.008 & 0.028 & Balanced \\
\hline
\end{tabular}

1.2. Experimental Procedures. The joining of stainless steel and CFRTP was conducted by a fiber laser welding system. This system comprises 1410RABB robot, $500 \mathrm{~W}$ fiber laser (continuous wave laser machine and the wavelength is $1080 \mathrm{~nm}$ ), laser processing head (the focal length is $120 \mathrm{~mm}$ ), air-actuated clamp and cooling system. The schematic diagram of the joining of stainless steel and CFRP by a laser is shown in Fig. 1. Firstly, the CFRTP overlaid with PPS additive on the surface was placed on the laser welding system and the stainless steel plate was placed above the PPS additive. After then, the stainless steel, PPS additive, and CFRTP were clamped by the air-actuated clamp which has a groove with a size of $60 \times 10 \times 5 \mathrm{~mm}$ in the upper one. The clamping pressure could be adjusted by controlling the air-actuator. During the laser joining, the laser beam would scan on the surface of stainless steel in the groove with the argon gas flow velocity of $30 \mathrm{l} / \mathrm{min}$. To investigate the effect of the processing parameters on the joint strength, the laser power and scanning speed were changed gradually. Firstly, the laser scanning speed, clamping 
pressure, and thickness of PPS were set as $5 \mathrm{~mm} / \mathrm{s}, 0.5 \mathrm{MPa}$, and $300 \mu \mathrm{m}$, respectively. While the laser power changes from 290 to $410 \mathrm{~W}$ with an interval of $30 \mathrm{~W}$. Then the laser power, clamping pressure, and thickness of PPS was set as $320 \mathrm{~W}, 0.5 \mathrm{MPa}$, and $300 \mu \mathrm{m}$, respectively. And the laser scanning speed changes from 3 to $6 \mathrm{~mm} / \mathrm{s}$. The detailed changing of the processing parameter is listed in Table 2. In all laser-joint specimens, the defocusing amount is $-20 \mathrm{~mm}$ (the laser beam diameter is $750 \mathrm{um}$ ).

T a b 1 e 2

The Detailed Processing Parameters of Laser-Joint Stainless Steel and CFRTP

\begin{tabular}{||c|c|c|c|c||}
\hline Sample & $\begin{array}{c}\text { Laser power } \\
(\mathrm{W})\end{array}$ & $\begin{array}{c}\text { Laser scanning } \\
\text { speed }(\mathrm{mm} / \mathrm{s})\end{array}$ & $\begin{array}{c}\text { Clamping pressure } \\
(\mathrm{MPa})\end{array}$ & $\begin{array}{c}\text { Thickness of PPS } \\
(\mu \mathrm{m})\end{array}$ \\
\hline A1 & 290 & 5 & 0.5 & 300 \\
$\mathrm{~A} 2$ & 320 & 5 & 0.5 & 300 \\
$\mathrm{~A} 3$ & 350 & 5 & 0.5 & 300 \\
A4 & 380 & 5 & 0.5 & 300 \\
A5 & 410 & 5 & 0.5 & 300 \\
$\mathrm{~B} 1$ & 320 & 3 & 0.5 & 300 \\
$\mathrm{~B} 2$ & 320 & 4 & 0.5 & 300 \\
$\mathrm{~B} 3$ & 320 & 5 & 0.5 & 300 \\
$\mathrm{~B} 4$ & 320 & 6 & 0.5 & 300 \\
B5 & 320 & 7 & 0.5 & 300 \\
\hline
\end{tabular}

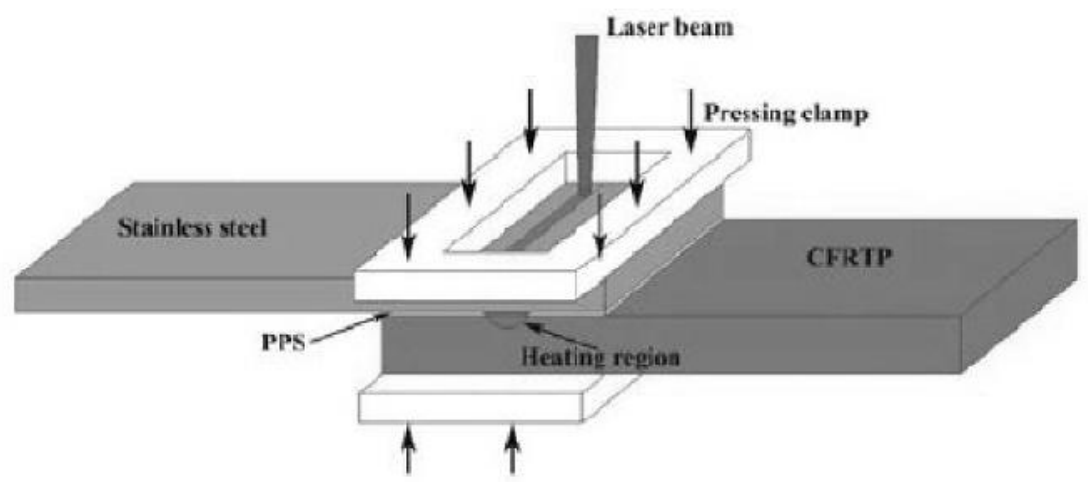

Fig. 1. The schematic diagram of stainless steel and CFRTP laser joining.

The laser-joined stainless steel and CFRTP samples were characterized by the tensile test, optical analysis, and scanning electron microscopy (SEM). The tensile test was performed in the UTM4304 electronic universal testing machine to evaluate the shear strength of the stainless steel and CFRTP joint. The Phenom Pro SEM was employed to analyze the fracture surface, and cross section of the laser joined sample. The specimen for cross-sectional observation is cut from the laser joined sample and polished by the conventional metallographic method.

1.3. Numerical Simulation. Though the temperature of the stainless steel surface could be detected during the laser joining, however, the temperature distribution in the stainless steel, PPS additive, and CFRTP could not be tested adequately. To explain the heat transfer during laser joining processing, the numerical simulation was performed to analyze the temperature distribution in the laser joining region. In our previous research, we have investigated the temperature distribution in 304 steel and CFRTP without PPS additive. The 
results exhibited that the temperature dropped obviously along the interface, and the fusion size of PPS in CFRTP increases with laser power, but they were not the linear relationship [16]. In the present research, the steel changed into 316 stainless steel, and PPS additive was added on the interface. The detailed conditions of the simulation mode were almost similar to our previous research. The initial temperature was set as $20^{\circ} \mathrm{C}$. The software ANSYS was applied to calculate the temperature distribution of the laser joint. The three-dimensional element model of laser joint was constructed by the SOLID70. To balance the simulating precision and computational efficiency, the size of the element in the laser scanning path was optimized. Table 3 exhibits the thermophysical parameters of the T700 and PPS used in the calculation.

T a b 1 e 3

Thermophysical Parameters of T700 and PPS

\begin{tabular}{|c|c|c|c|c|c|c||}
\hline Material & $\begin{array}{c}\text { Specific } \\
\text { heat } \\
\left(\mathrm{J} /\left(\mathrm{kg} \cdot{ }^{\circ} \mathrm{C}\right)\right)\end{array}$ & $\begin{array}{c}\text { Thermal } \\
\text { conductivity } \\
\left(\mathrm{W} /\left(\mathrm{m} \cdot{ }^{\circ} \mathrm{C}\right)\right)\end{array}$ & $\begin{array}{c}\text { Density } \\
\left(\mathrm{kg} / \mathrm{m}^{3}\right)\end{array}$ & $\begin{array}{c}\text { Melting } \\
\text { point } \\
\left({ }^{\circ} \mathrm{C}\right)\end{array}$ & $\begin{array}{c}\text { Glass transition } \\
\text { temperature } \\
\left({ }^{\circ} \mathrm{C}\right)\end{array}$ & $\begin{array}{c}\text { Decomposition } \\
\text { temperature } \\
\left({ }^{\circ} \mathrm{C}\right)\end{array}$ \\
\hline T700 & 712 & 6.5 & 1760 & 3000 & - & - \\
PPS & 1544 & 0.278 & 1350 & 280 & 170 & 400 \\
\hline
\end{tabular}

\section{Results and Discussion.}

2.1. Microstructure of the CFRTP and PPS Additive. The typical microstructures of PPS based CFRTP and PPS additive are shown in Fig. 2. The PPS based CFRTP is mainly composed of black-grey carbon fiber and white-grey PPS matrix, as shown in Fig. 2 a. From the SEM image, it can be found that the carbon fibers are overlapped layer by layer, and most carbon fibers are packed and bonded together by the PPS. Based on the macroscopic observation, the layer of carbon fiber is weaved as decussate structure.
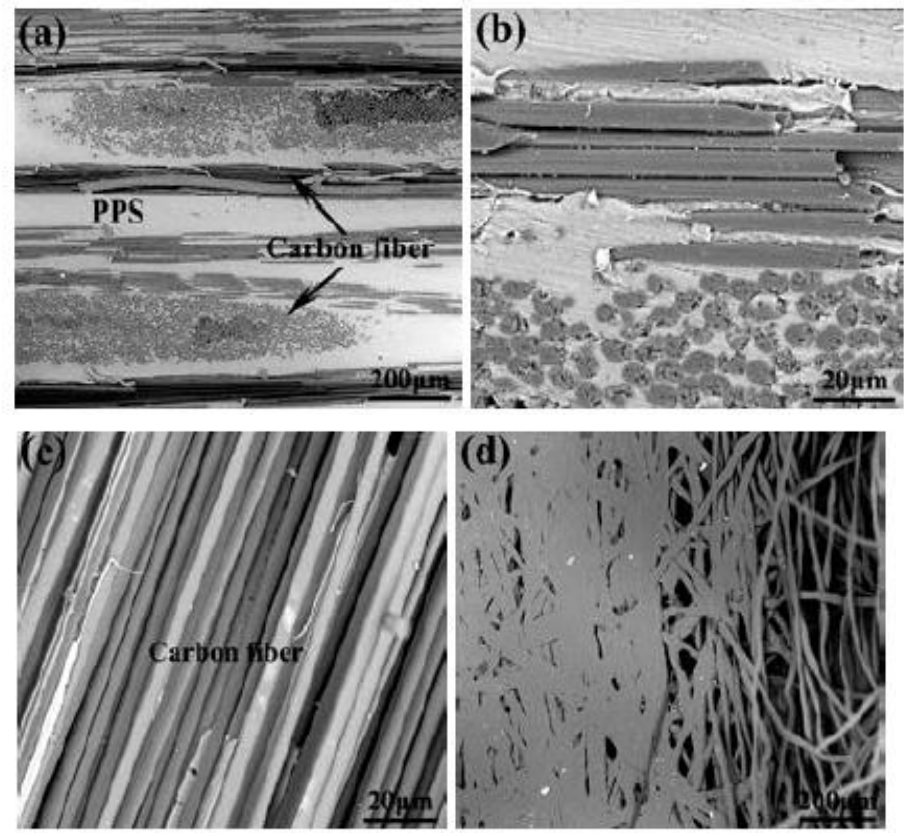

Fig. 2. Morphology of the PPS based CFRTP and PPS additive: (a) CFRTP with the overlapping of carbon fibers; (b) carbon fiber array; (c) carbon fibers packed by the PPS; (d) PPS additive. 
The layer of carbon fiber is about $200 \mu \mathrm{m}$ in thickness. It also can find some layer with higher thickness. The observation on the layer of carbon fiber exhibits that they have the average size of $6 \mu \mathrm{m}$ in diameter, as shown in Fig. 2b. Moreover, the distribution of PPS in the CFRTP is not uniformly, and the interface of the carbon fiber layer prefers to be the vacancy of PPS. The observation on the torn PPS based CFRTP exhibits that the carbon fiber has good integrity with a regular arrangement, as shown in Fig. 2c. The SEM analysis on the PPS additive reveals that the wires of PPS are overlapped randomly, and there is relatively high porosity, as shown in Fig. 2d. Based on the SEM image, the PPS wire has the size of $20-30 \mu \mathrm{m}$ in diameter.

2.2. Characterization on the Laser Joined Stainless Steel and CFRTP. The macrograph of the laser joined the stainless steel and CFRTP is shown in Fig. 3. The laser scanning results in the ignited feature in the stainless steel which exhibits light oxidation on the laser scanning track, as shown in Fig. 3a. Observation on the side of CFRTP and PPS displays that the PPS has no any changes but the PPS additive between the stainless steel and CFRTP has been melted, as shown in Fig. 3b. Based on the previous research [16, 17], the laser-scanned surface of the steel would reach $1800^{\circ} \mathrm{C}$, and the interface of the stainless steel and CFRTP would reach $400^{\circ} \mathrm{C}$. That indicates the heat from the laser scanning would be exceeded for the melting of the PPS additive. Then it can ensure the PPS additive, and the surface of the CFRTP would be merged with each other and then bonded with the stainless steel. Therefore, the roughness of the stainless steel surface is helpful, which increases the bonding surface and bonding force.
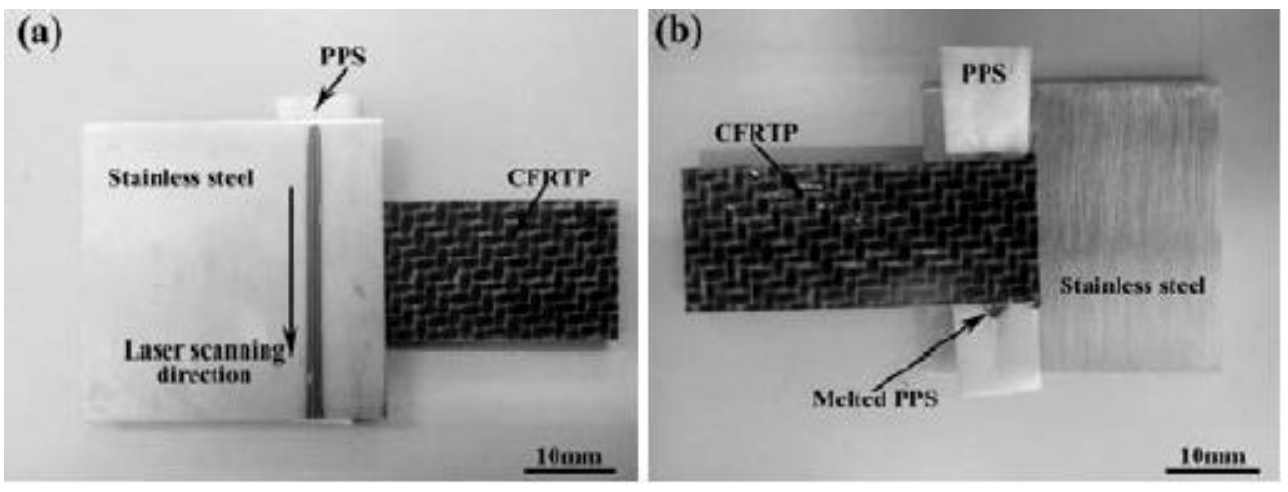

Fig. 3. Morphology of the laser-joined CFRTP and stainless steel with PPS additive: (a) steel with the laser scanned; (b) PPS additive with the melting feature.

The observation on the interface of the laser joined CFRTP, and stainless steel reveals that the CFRTP still can be bonded on the stainless steel even without the PPS additive, as shown in Fig. 4a. Such a joined state should be attributed to the existence of PPS in the CFRTP. During the laser joining, the laser scanning on the stainless steel would increase the temperature of the steel surface to about $400^{\circ} \mathrm{C}$, which could melt the PPS to liquid and spread on the gap of stainless steel and CFRTP [16]. Due to the limited amount of PPS in the CFRTP, the melted PPS could not spread on the gap uniformly. The addition of PPS additive would deal with the problem, as shown in Fig. 4b. It can be seen that the molten PPS has filled the gap of steel and CFRTP, and moreover some molten PPS additive has flowed out of the gap and spread on the adjacent stainless steel, but the distribution is not evenly. Based on the observation above, there are vacancies in the CFRTP without PPS, which may influence the bonding force between the carbon fibers. If the melted PPS volume is sufficient, it would fill the vacancy and improve the bonding strength.

The observation on the laser scanned stainless steel reveals that the laser scanning influences the microstructure greatly, as shown in Fig. 5. It can be seen that there are fusion 

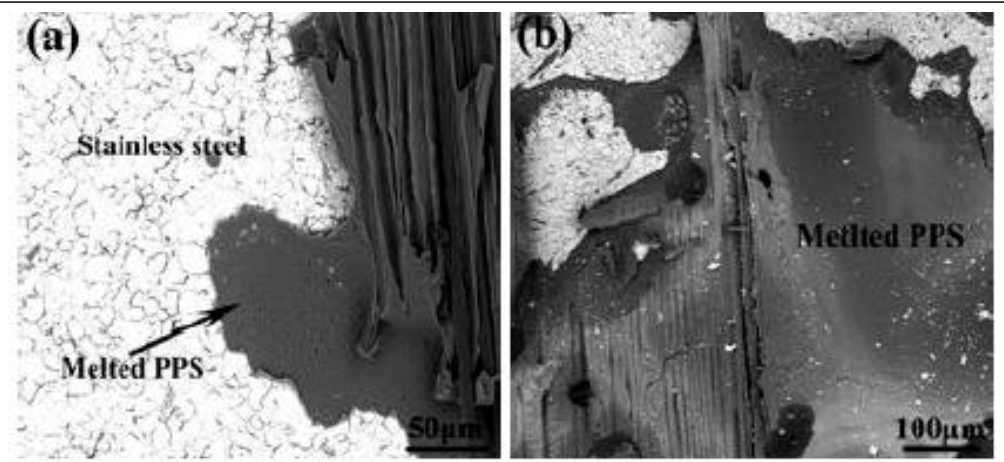

Fig. 4. Morphology of the interface of the laser joined CFRTP and stainless steel without PPS additive (a) and with PPS additive (b).
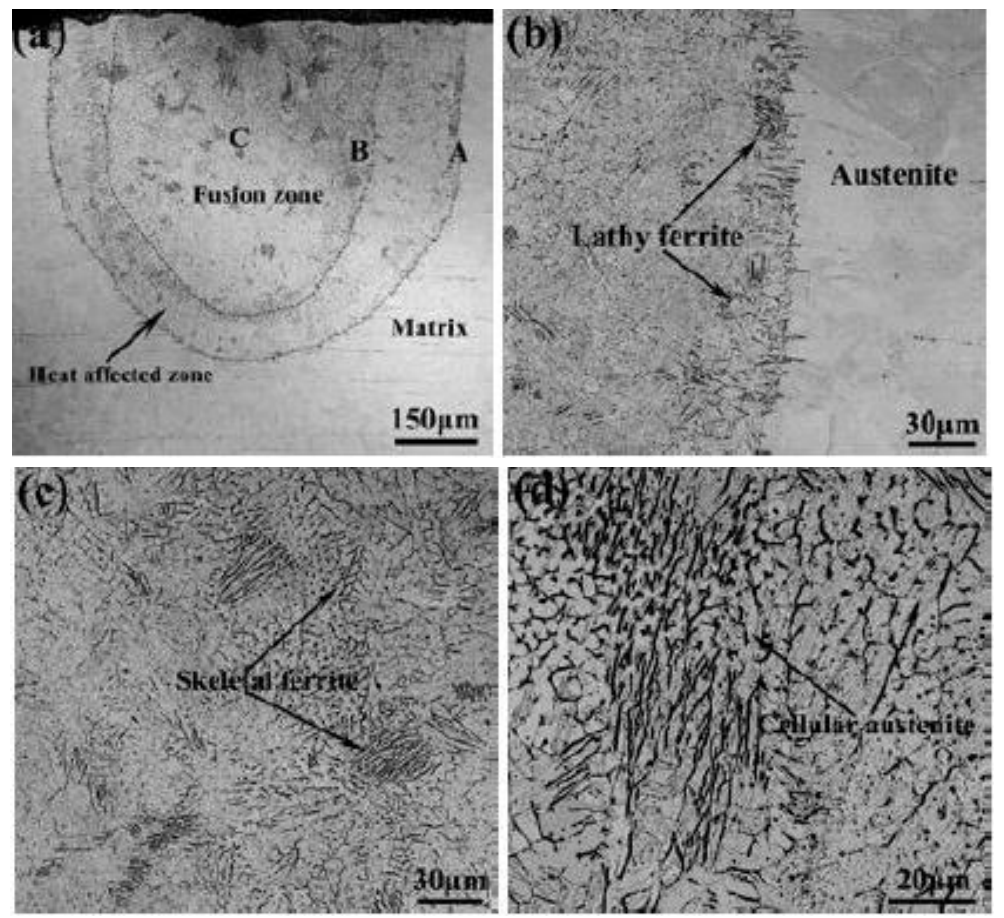

Fig. 5. (a) macrograph of the laser-scanned stainless steel; (b) microstructure of the stainless steel along the interface of matrix and $\operatorname{HAZ}(A$ position); (c) microstructure of the stainless steel adjacent to the fusion zone ( $B$ position); (d) microstructure of the stainless steel in the fusion zone $(C$ position).

zone and heat-affect zone (HAZ) in the steel, which exhibits hemi-ellipsoidal shape, as shown in Fig. 5a. The fusion zone is marked by the blue dash line and has the width of about $470 \mu \mathrm{m}$ and the depth of about $580 \mu \mathrm{m}$. The HAZ embraces the fusion zone and has the width of $100-180 \mu \mathrm{m}$, which is marked between the red dash line and blue dash line. The fusion zone almost has the cone shape, and its center is $300 \mu \mathrm{m}$ from the surface. Such a morphology of fusion and HAZ should be attributed to the defocus of the laser. Based on the microstructure analysis, the stainless steel exhibits homogeneous grains with the average size of $20 \mu \mathrm{m}$, but the laser scanning changes the microstructure, as shown in Fig. $5 \mathrm{~b}$ and c. In the HAZ, the lathy ferrite mainly precipitates along the original grain boundary or twin boundary, which separates the original grain and refines the structure. 
Moreover, a distinct boundary formed between the HAZ and matrix. With the observation proceeding to the fusion zone, the ferrite becomes coarse and increases, which forms the skeletal structure. There is no distinct boundary between the HAZ and the fusion zone. However, the fusion zone could be distinguished by the morphology and amount of the ferrite $[18,19]$. In the fusion zone, the skeletal ferrite and cellular austenite is the main characteristic. Based on the researches [20,21], the microstructure of the fusion zone and $\mathrm{HAZ}$ is influenced by the $\mathrm{Cr}_{e q} / \mathrm{Ni}_{e q}$ ratio and cooling rate. The higher cooling rate and $\mathrm{Cr}_{e q} / \mathrm{Ni}_{e q}$ ratio could promote the formation of cellular structure. In the present research, the relative high $\mathrm{Cr}$ content and rapid laser scanning speed would promote the formation of ferrite with intercellular or interdentritic structure. Therefore, one can see the skeletal ferrite separates the austenite into small cells. Such a refined structure might be helpful to the improvement of the strength [22-25].

2.3. Effect of Laser Power on the Laser Joining Stainless Steel and CFRTP. To investigate the effect of processing parameters on the bonding force of laser joining stainless steel and CFRTP, the laser power and scanning speed were changed gradually, and the shear strength of the laser joining specimens was tested. During investigating the effect of laser power, the clamping pressure, laser scanning speed, and thickness of PPS were set as $0.5 \mathrm{MPa}, 5 \mathrm{~mm} / \mathrm{s}$, and $300 \mu \mathrm{m}$, respectively. The shear strength of the stainless steel/CFRTP joints with different laser power is shown in Fig. 6. The variation of shear strength with power exhibits parabolic tendency. Firstly, the stainless steel/CFRTP joint exhibits an increased shear strength and attains the maximum value of $15.8 \mathrm{MPa}$ at $320 \mathrm{~W}$. When the laser power increases to $350 \mathrm{~W}$, the shear strength of stainless steel/CFRTP joint only slightly decreases. After then the shear strength decreases sharply with laser power growing further. Based on the SEM observation above, the high laser power is beneficial the melting of PPS additive and PPS in CFRTP, which could promote the merging of PPS additive and CFRTP and then improve the bonding force between the stainless steel and CFRTP. However, if the laser power is much higher, the improved fluidity of molted PPS and clamping pressure would result in its overflowing out of the gap between stainless steel and CFRTP, which is detrimental to the bonding.

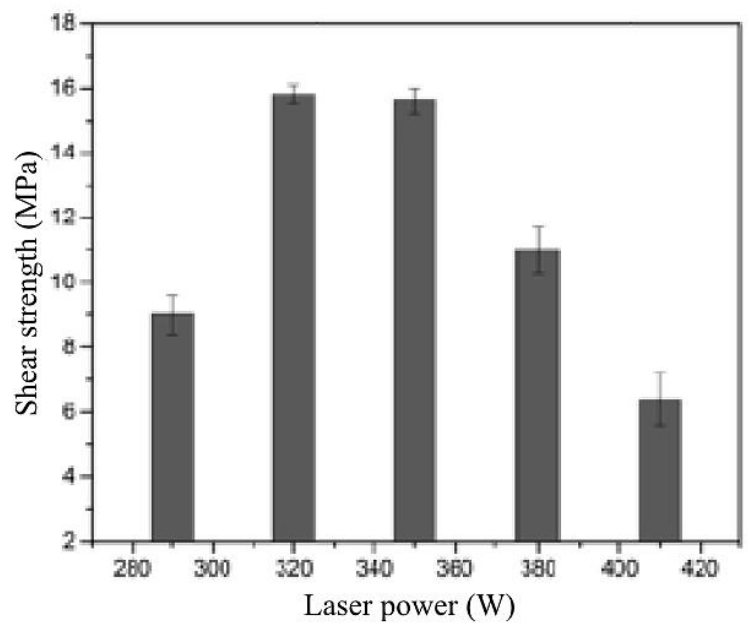

Fig. 6. The shear strength of the stainless steel/CFRTP joints with different laser power.

The observations on the debonding surface of the stainless steel/CFRTP joints with different power show that they almost exhibit the similar feature with the debonding along the interface of PPS, as shown in Fig. 7. The difference is the fraction of PPS additive that is residual on the CFRTP. The stainless steel/CFRTP joint with a laser power of $290 \mathrm{~W}$ has 
no PPS additive left on the CFRTP, which indicates the bonding force between CFRTP and PPS additive is lower than that between PPS additive and stainless steel. With the laser power increasing, the amount of PPS additive remained on the CFRTP increases, and the air hole is observed on the stainless steel/CFRTP joints with a laser power of 350 and $400 \mathrm{~W}$. That means that the decomposition of PPS additive occurs during the laser joining, which indicates the PPS additive is overheated. The excess energy would lead to the molten PPS flows out of the gap of stainless steel and CFRTP, which decreases the shear strength. Moreover, the formation of an air hole along interface is also detrimental to the bonding of the joint.
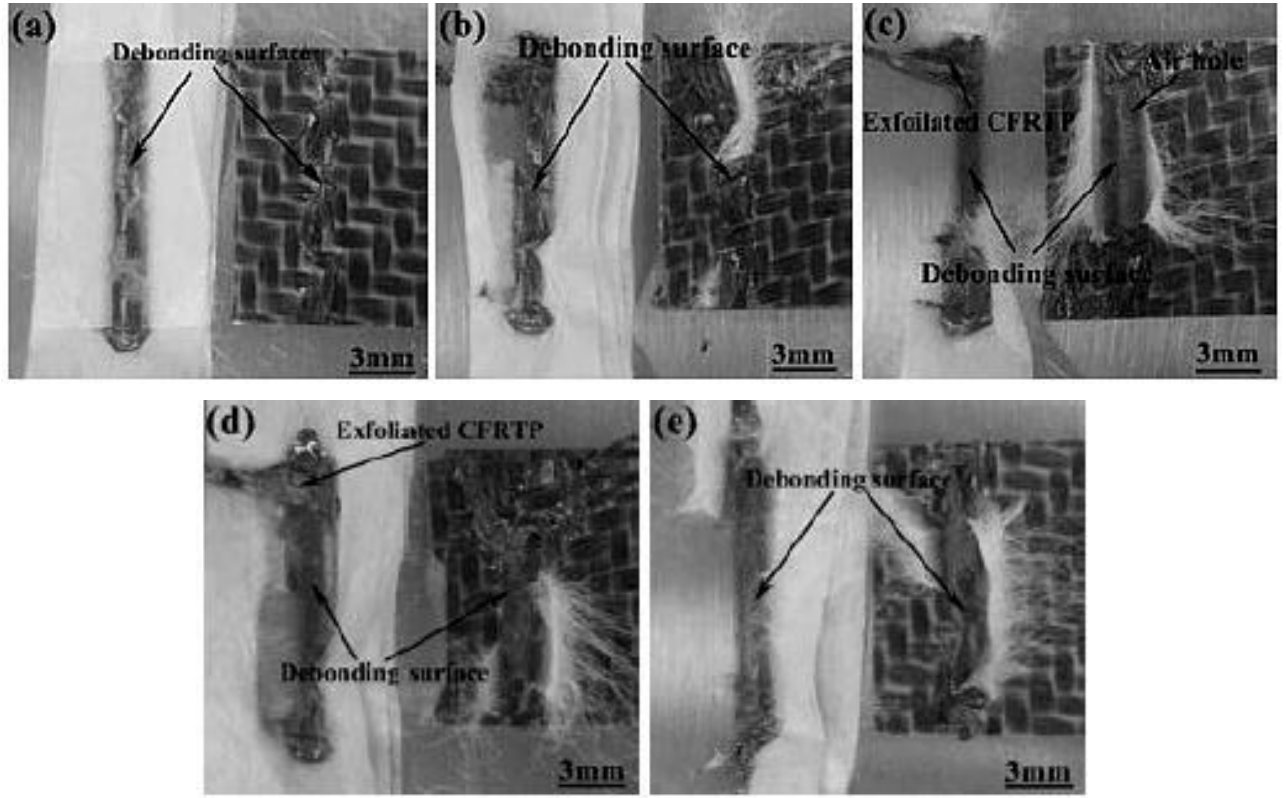

Fig. 7. The morphology of debonding surface of the stainless steel/CFRTP joints with different laser power after tensile: 290 (a), 320 (b), 350 (c), 380 (d), and $410 \mathrm{~W}$ (e).

The statistical analysis on the surface of stainless steel/CFRTP joints with different power shows that the fusion width of the stainless steel increases with the laser power increasing and they almost have the linear relationship, as shown in Fig. 8a. Moreover, the fusion width of the PPS additive also increases with the laser power increasing, but they do not have the linear relationship, as shown in Fig. 8b. Based on the analysis on the debonding surface, the PPS additive decomposes at the laser power above $350 \mathrm{~W}$, which would consume some energy and influence the width of the melted PPS additive [17]. Besides, the analysis on the surface of CFRTP of $410 \mathrm{~W}$ specimen reveals that there are some $\mathrm{Cr}$ element, which suggested that the diffusion between the stainless steel and CFRTP has taken place. Due to the mechanical bonding between PPS additive and stainless steel, the element diffusion indicates the high temperature of the melted PPS. Combining with the observation on the debonding surface, it can be concluded that the excessive laser power could overheat the PPS additive, which results in its spreading and overflowing but decreases the bonding with the stainless steel.

2.4. Effect of Laser Scanning Speed on the Laser Joining Stainless Steel and CFRTP. To explore the influence of laser scanning speed on the bonding force of stainless steel/CFRTP joint, the laser scanning speed is changed from 3 to $7 \mathrm{~mm} / \mathrm{s}$, while the laser power, clamping pressure and thickness of PPS were set as $320 \mathrm{~W}, 0.5 \mathrm{MPa}$, and $300 \mu \mathrm{m}$, respectively. The shear strength of the stainless steel/CFRTP joints with different laser 


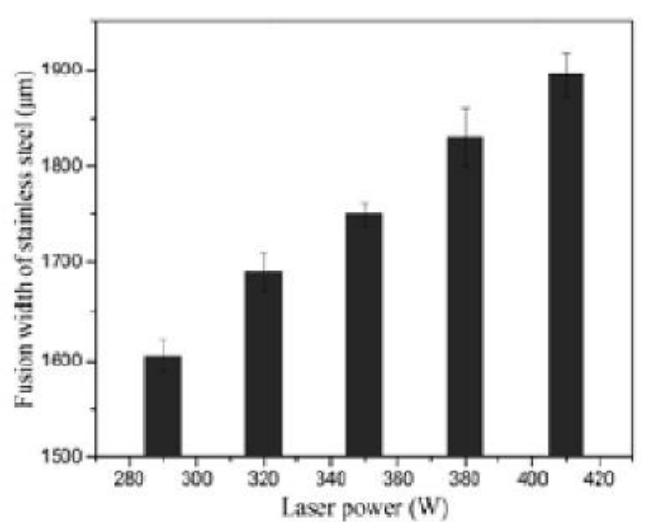

a

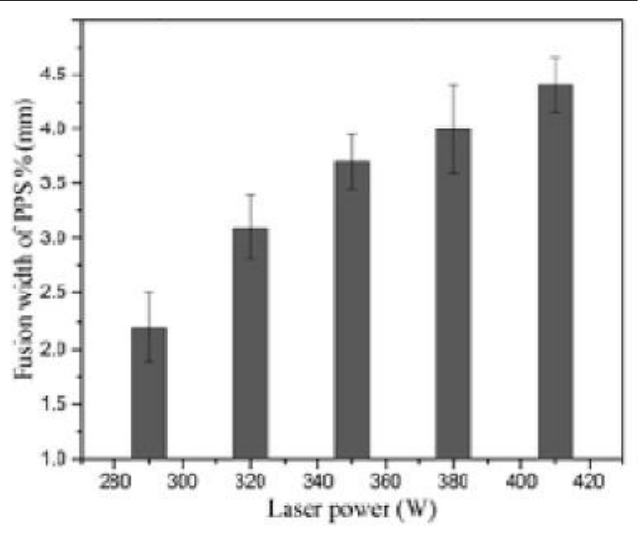

$\mathrm{b}$

Fig. 8 The fusion width of stainless steel (a) and the PPS additive (b) in the stainless steel/CFRTP joint with different laser power.

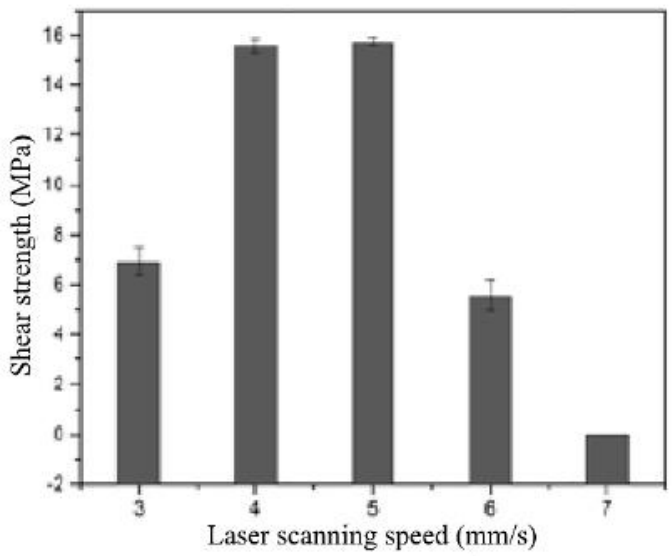

Fig. 9. The shear strength of the stainless steel/CFRTP joints with different laser scanning speed.

scanning speed is exhibited in Fig. 9. The shear strength of the stainless steel/CFRTP joint is improved from 7 to $16 \mathrm{MPa}$ when the laser scanning speed increases from 3 to $4 \mathrm{~mm} / \mathrm{s}$. At the laser scanning speed of $5 \mathrm{~mm} / \mathrm{s}$, the shear strength of the stainless steel/CFRTP joint is slightly improved. That indicates the stainless steel/CFRTP joint could obtain the optimum value if the scanning speed is chosen between 4 and $5 \mathrm{~mm} / \mathrm{s}$. With the laser scanning speed exceeds $5 \mathrm{~mm} / \mathrm{s}$, the shear strength of the stainless steel/CFRTP joint decreases sharply. The laser joined specimen with $7 \mathrm{~mm} / \mathrm{s}$ almost has no shear strength.

The observations on the debonding surface of the stainless steel/CFRTP joints with different laser scanning speed are given in Fig. 10. The morphology of the debonding surface changes with laser scanning speed greatly. At the laser scanning speed of $3 \mathrm{~mm} / \mathrm{s}$, the surfaces of stainless steel and CFRTP both have the residual melted PPS. But the surface of CFRTP exhibits the overheating feature, which is detrimental to the bonding effect. When the laser scanning speed increases to 4 and $5 \mathrm{~mm} / \mathrm{s}$, there is obvious PPS residual on the surface of stainless steel and CFRTP, which indicates the bonding force of PPS additive with CFRTP and stainless steel is good. Therefore, it could be understood the stainless steel/CFRTP joints at the scanning speed below $5 \mathrm{~mm} / \mathrm{s}$ are all have relative good shear strength. However, there are few PPS additive adhered on the surface of stainless steel or CFRTP in the joint with laser scanning speed of 6 and $7 \mathrm{~mm} / \mathrm{s}$. Moreover, the laser 

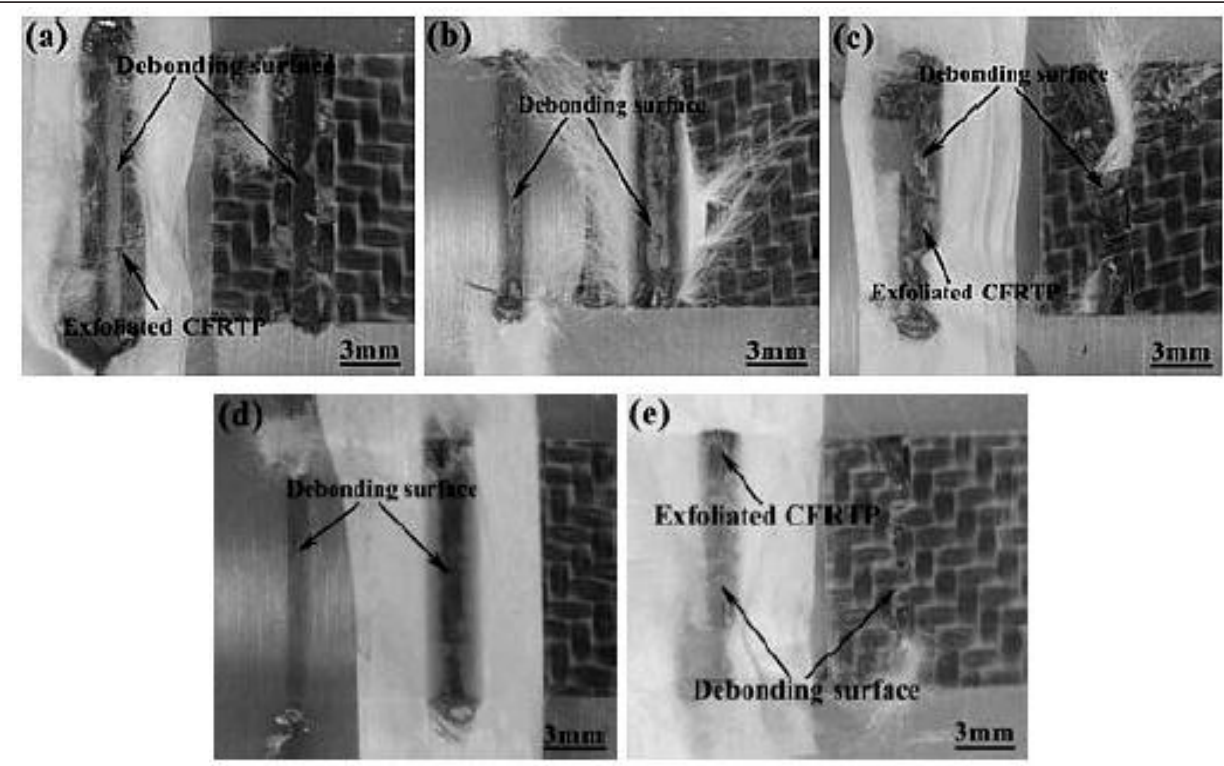

Fig. 10. The morphology of debonding surface of the stainless steel/CFRTP joint with different laser scanning speed after tensile: 3 (a), 4 (b), 5 (c), 6 (d), and $7 \mathrm{~mm} / \mathrm{s}$ (e).

joined specimen with laser scanning speed of $7 \mathrm{~mm} / \mathrm{s}$ has not melted the PPS thoroughly and coalesced with the CFRTP, which means that the heat released from the stainless steel is not high enough.

The statistical analysis of the debonding surface of the stainless steel/CFRTP joints demonstrates that the fusion width of stainless steel decreases obviously with the increased laser scanning speed, as shown in Fig. 11. Moreover, the fusion width of stainless steel almost has the linear relationship with the laser scanning speed. The combination with the observation of debonding surface, it could be summarized that the fast laser scanning speed would not provide enough energy to the stainless steel. As the results, the heat transferred to the surface of CFRTP is limited which can not melt PPS additive. Based on the previous researches $[15,26]$, the bonding effect between the stainless steel and CFRTP is mainly influenced by the bonding interface. Due to the significant difference between the CFRTP and stainless steel, there would be no atom or molecular binding. The melted PPS could be mechanically bonded with the stainless steel and molecular bonding with the CFRTP, so the energy from the laser is essential, which determines the state of the PPS additive.

To investigate the heat transfer during the laser joining, the simulation analysis of the temperature distribution of the stainless steel/CFRTP joint is carried out. Figure 12 shows the simulation results with processing parameters of laser power $320 \mathrm{~W}$, scanning speed $5 \mathrm{~mm} / \mathrm{s}$ and laser beam radius $0.75 \mathrm{~mm}$. The laser processing generates excellent energy concentration on the surface of stainless steel. Due to the heat transfer, the temperature of the interface is lower than that of the stainless steel surface. Moreover, the temperature drops significantly with the position going to the CFRTP. At the interface of stainless steel and PPS additive, the temperature reaches $560^{\circ} \mathrm{C}$ that is higher than the melting point of the PPS additive. Therefore, the heat from the laser scanned stainless steel would melt the PPS between the stainless steel and CFRTP. However, there are distinct stages between the stainless steel and CFRTP. The temperature drops sharply in the PPS additive and almost reaches the melting point of PPS on the surface of CFRTP when the PPS additive is $300 \mu \mathrm{m}$. That indicates the heat would be sufficient enough to melt the PPS matrix and merge it with the PPS additive. With the position going into the CFRTP, the temperature drops below the melting point. Moreover, the rapid temperature decreasing also suggests the energy from 


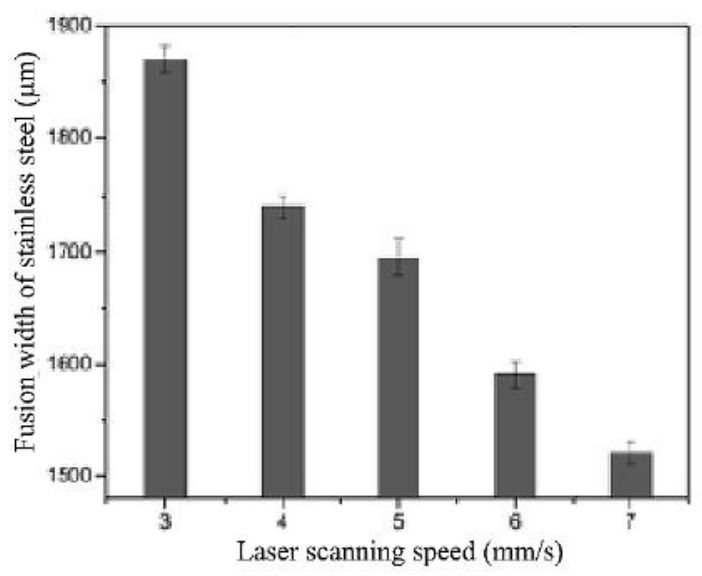

Fig. 11. The fusion width of the stainless steel in the stainless steel/CFRTP joints with different laser scanning speed.

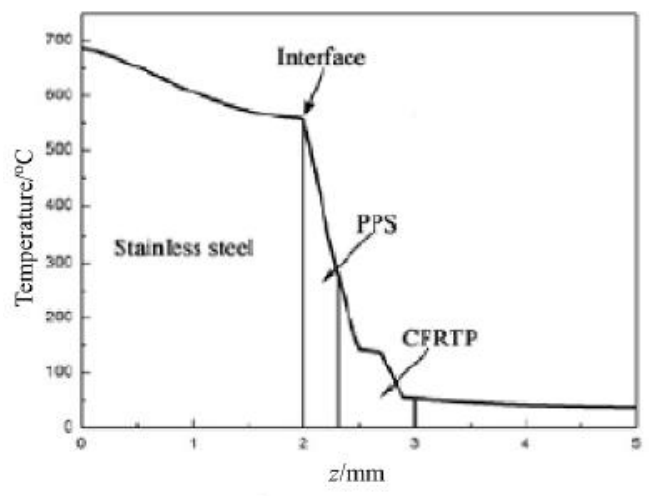

a

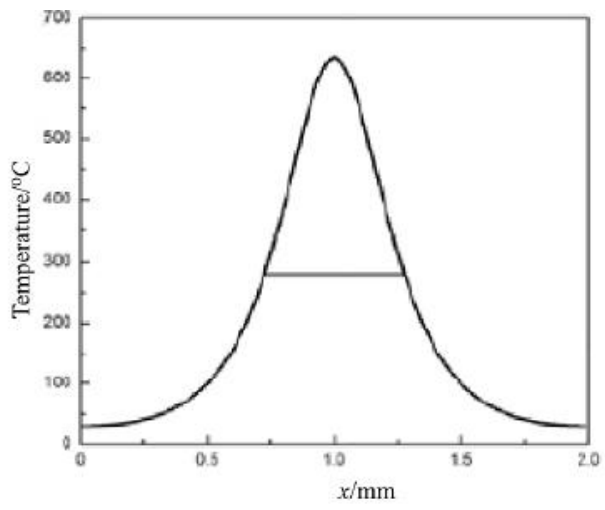

b

Fig. 12. The temperature distribution along the cross section of the stainless steel/CFRTP joint (a) and on the surface of the PPS additive (b).

laser should be enough if the PPS additive and PPS in the CFRTP surface needs to be melted and merged entirely. The simulated result on the PPS additive also exhibits a fusion region with a width of $2 \mathrm{~mm}$ has the temperature above the melting point, which indicates the PPS additive in such a region would be melted. Such simulated results confirm the experimental observation above. The bonding effect of the stainless steel/CFRTP is mainly affected by the laser scanning speed and laser power which determines the absorbed energy.

According to the previous researches [17, 26, 27], the bonding force of the laser joined CFRTP and metal is mainly determined by the external energy which remelts the PPS additive and PPS matrix of the CFRTP. Therefore, it can be understood that the bonding force of the stainless steel/CFRTP joint exhibits parabolic tendency with the variation of laser scanning speed and power. Because the low scanning speed and high laser power would result in the excessive energy, which could promote the decomposition of PPS and the overflow of melted PPS. The decomposition of PPS would release gas and form the air bubble, which weakens the bonding between the stainless steel and CFRTP. Moreover, the overflow of PPS also decreases the bonding transition region between the stainless steel and CFRTP, which is detrimental to the bonding force. However, if the laser scanning speed is high and the laser power is low, the absorbed heat of the PPS would be 
insufficient, especially the PPS in CFRTP. As a result, the PPS adjacent to the CFRTP and PPS in the surface of CFRTP could not be melted thoroughly. Then the merging between the PPS additive and CFRTP would be significantly weakened. Indeed, the clamping pressure might generate influence on the joint, because the consistent clamping pressure is beneficial to the heat transfer, but such an effect should cooperate with the external energy from laser joining. Whatever, the laser power and scanning speed should be the main influence factors during laser joining steel and CFRTP.

Conclusions. The CFRTP can be joined with the 316 stainless steel by the fiber laser but the laser scanning on the stainless steel results in the formation of the HAZ and fusion zone. In the HAZ, the lathy ferrite precipitates along the boundary, which refines the austenite; while in the fusion zone, the ferrite forms the skeletal structure and separates the austenite into a small cellular structure. Compared with the original microstructure of stainless steel, the laser joining refines the microstructure in the fusion and HAZs. With the increasing of laser power and scanning speed, the shear strength of the laser joined stainless steel/CFRTP joint both rises firstly and then declines. The high laser power or low laser scanning speed would overheat the PPS and lead to the decomposition, but the low laser power or high laser scanning speed would reduce the transferred heat and lead to the insufficient fusion of PPS. The stainless steel/CFRTP joint obtains the maximum shear strength value at the laser power of 320-350 W and laser scanning speed of 4-5 mm/s.

Acknowledgments. The authors are grateful to the support of Shenzhen Basic Research Projects (JCYJ20150529162228734, JCYJ20160427170611414, and JCYJ20170306141506805).

1. X. L. Zhao and L. Zhang, "State-of-the-art review on FRP strengthened steel structures," Eng. Struct., 29, 1808-1823 (2007).

2. F. Lambiase, S. Genna, C. Leone, and A. Paoletti, "Laser-assisted direct-joining of carbon fibre reinforced plastic with thermosetting matrix to polycarbonate sheets," Opt. Laser Technol., 94, 45-58 (2017).

3. G. Williams, R. Trask, and I. Bond, "A self-healing carbon fiber reinforced polymer for aerospace applications," Compos. Part A-Appl. S., 38, No. 6, 1525-32 (2007).

4. A. Mayyas, A. Qattawi, M. Omar, and D. Shan, "Design for sustainability in automotive industry: a comprehensive review," Renew. Sust. Energ. Rev., 16, No. 4, 1845-62 (2012).

5. Z. Zhang, J. Shan, X. Tan, and J. Zhang, "Improvement of the laser joining of CFRP and aluminum via laser pre-treatment," Int. J. Adv. Manuf. Technol., 90, Nos. 9-12, 3465-3472 (2017).

6. G. Marannano and B. Zuccarello, "Numerical experimental analysis of hybrid double lap aluminum-CFRP Joints,” Compos. Part B-Eng., 71, 28-39 (2015).

7. J. Kweon, J. Jung, T. Kim, et al., "Failure of carbon composite-to-aluminum joints with combined mechanical fastening and adhesive bonding," Compos. Struct., 75, 192-198 (2006).

8. P. P. Camanho, A. Fink, A. Obst, and S. Pimenta, "Hybrid titanium-CFRP laminates for high-performance bolted joints," Compos. Part A-Appl. S., 40, No. 12, 1826-1837 (2009).

9. S. M. Goushegir, "Friction spot joining (FSPJ) of aluminum-CFRP hybrid structures," Weld World, 60, No. 6, 1073-1093 (2016).

10. J. Min, Y. Li, J. Li, et al., "Friction stir blind riveting of carbon fiber-reinforced polymer composite and aluminum alloy sheets," Int. J. Adv. Manuf. Technol., 76, No. 5, 1403-1410 (2015). 
11. S. Katayama and Y. Kawahito, "Laser direct joining of metal and plastic," Scripta Mater., 59, 1247-1250 (2008).

12. X. Tan, J. Shan, and J. Ren, "Effects of Cr plating layer on shear strength and interface bonding characteristics of mild steel/CFRP joint by laser heating," Acta Metall. Sin., 49, 751-756 (2013).

13. X. H. Tan, J. Zhang, J. G. Shan, et al., "Characteristics and formation mechanism of porosities in CFRP during laser joining of CFRP and steel," Compos. Part B-Eng., 70, 35-43 (2015).

14. L. Y. Sheng, F. Yang, T. F. Xi, et al., "Influence of heat treatment on interface of $\mathrm{Cu} / \mathrm{Al}$ bimetal composite fabricated by cold rolling," Compos. Part B-Eng., 42, No. 6, 1468-1473 (2011).

15. K. W. Jung, Y. Kawahito, and S. Katayama, "Laser direct joining of carbon fibre reinforced plastic to stainless steel," Sci. Technol. Weld Joint, 16, No. 8, 676-80 (2011).

16. J. Jiao, Q. Wang, F. Wang, et al., "Numerical and experimental investigation on joining CFRTP and stainless steel using fiber lasers," J. Mater. Process. Tech., 240, 362-369 (2017).

17. J. Jiao, Z. Xu, Q. Wang, et al., "CFRTP and stainless steel laser joining: Thermal defects analysis and joining parameters optimization," Opt. Laser Technol., 103, 170-176 (2018).

18. H. Di, Q. Sun, X. Wang, and J. Li, "Microstructure and properties in dissimilar/ similar weld joints between DP780 and DP980 steels processed by fiber laser welding," J. Mater. Sci. Technol., 33, No. 12, 1561-1571 (2017).

19. L. J. Wang, L. Y. Sheng, and C. M. Hong, "Influence of grain boundary carbides on mechanical properties of high nitrogen austenitic stainless steel," Mater. Design, 37, 349-355 (2012).

20. M. Alali, I. Todd, and B. P. Wynne, "Through-thickness microstructure and mechanical properties of electron beam welded $20 \mathrm{~mm}$ thick AISI 316L austenitic stainless steel," Mater. Design, 130, 488-500 (2017).

21. L. Y. Sheng, F. Yang, T. F. Xi, et al., "Microstructure and elevated temperature tensile behaviour of directionally solidified nickel based superalloy," Mater. Res. Innov., 17, No. S1, 101-106 (2013).

22. L. Y. Sheng, F. Yang, T. F. Xi, et al., "Microstructure evolution and mechanical properties of $\mathrm{Ni}_{3} \mathrm{Al} / \mathrm{Al}_{2} \mathrm{O}_{3}$ composite during self-propagation high-temperature synthesis and hot extrusion," Mater. Sci. Eng. A, 555, 131-138 (2012).

23. L. Y. Sheng, B. N. Du, B. J. Wang, et al., "Hot extrusion effect on the microstructure and mechanical properties of an $\mathrm{Mg}-\mathrm{Y}-\mathrm{Nd}-\mathrm{Zr}$ alloy," Strength Mater., 50, No. 1, 184-192 (2018).

24. L. Y. Sheng, W. Zhang, J. T. Guo, et al., "Microstructure and mechanical properties of $\mathrm{Ni}_{3} \mathrm{Al}$ fabricated by thermal explosion and hot extrusion," Intermetallics, 17, No. 7, 572-577 (2009).

25. L. Sheng, F. Yang, T. Xi, et al., "Microstructure and room temperature mechanical properties of NiAl-Cr (Mo)-(Hf, Dy) hypoeutectic alloy prepared by injection casting," Trans. Nonferrous Met. Soc. China, 23, No. 4, 983-990 (2013).

26. K. W. Jung, Y. Kawahito, and S. Katayama, "Laser direct joining of carbon fiberreinforced plastic to stainless steel," Sci. Technol. Weld Joint, 16, 676-680 (2011).

27. M. Wahba, Y. Kawahito, and S. Katayama, "Laser direct joining of AZ91D thixomolded Mg alloy and amorphous polyethylene terephthalate," J. Mater. Process. Tech., 211, No. 6, 1166-1174 (2011). 